\title{
Surgery from experimental research to clinical application and vice-versa
}

\author{
Orlando de Castro e Silva* \\ * Full Professor and Head of Division of Gastroenterology, Department of Surgery and Anatomy, Ribeirão Preto Faculty of Medicine, \\ University of São Paulo, Brazil.
}

Producing knowledge is of fundamental importance and disseminating knowledge is a moral and ethical task that must not be neglected, especially by those who belong to a university institution strongly committed to teaching, research and patient care. The words science, technology and research denote three highly complex concepts of human activity. In medicine, and in surgery in particular, this complex triad is extremely important when it acts as an effective way of obtaining direct progress in surgery in a medical school, with a significant influence on the wellbeing of the patients.

\section{Research and clinical practice}

We have always considered the involvement in the production of knowledge to be an absolutely necessary component for those with professional ties to the University as teachers. In addition, we believe that the extrapolation of attitudes and practices concerning scientific work to the remaining fields of academic work contributes to the improvement of teaching, of the extension of services to Society and of the administration of the University itself. Professional competence in research is not incompatible with technical-surgical competence ${ }^{1,2,3}$. There are countless examples of surgical investigators who execute well both activities. In particular, we believe that the two skills complement each other and should definitely be practiced in a continuous manner. The involvement in research activity on a day-to-day basis, in addition to fulfilling its major objective of contributing to the generation of knowledge, in our opinion, can and should have a relevant influence on other areas of professional activity.

\section{Training people}

The first area concerns the training of people in graduate courses, in projects of scientific initiation, in postgraduation stricto sensu, in Master's or Doctoral investigations, and also in post-graduation sensu lato, i.e., in medical residency, ${ }^{4,5}$. Engaging in a research project may have an important impact on the acquisition of attitudes and skills that will be favorable in any area of professional activity, thus justifying the inclusion of research in any educational or training program $\mathrm{m}^{2,3,4,5}$.

\section{Condition of research work}

Another contribution of scientific research is the creation of conditions that will permit a person or a group of investigators to carry out work of their interest by applying functioning methods. Thus research is an essential instrument for the creation of a Group with natural vocational diversity and with broad experimental and clinical training. I would like to mention in particular the interaction with several Departments of the Faculty of Medicine of Ribeirão Preto and with other Institutions inside and outside the University of São Paulo, developed over a period of decades and of fundamental importance for reaching the goals proposed ${ }^{5,6}$.

\section{Application of the methods created}

Another repercussion of any type of scientific investigation is related to the development of specific functional methods that, after appropriate standardization, start to be used in health care, in diagnostic evaluation and in the therapeutic definition of special cases ${ }^{7}$. Examples of the interpretation of these research activities are the recent studies on the effect of hyperbaric oxygen therapy on hepatic regeneration ${ }^{8}$ and their clinical application to patients with hepatic artery thrombosis and primary hepatic dysfunction post-liver transplantation ${ }^{9}$. Similarly, in our Group the use of photodynamic therapy for the treatment of tumors is gaining space in the field of the therapeutic possibilities for gastroenterology, especially regarding tumors of the liver and of the esophagus. We may also mention the use of laser fluorescence spectroscopy, which is already being used for patients with tumors of the liver, pancreas and esophagus. This method, developed and refined in collaboration with the Institute of Physics of São Carlos, University of São Paulo, permits not only a diagnosis of the tumor, but also the level of the safety margin for tumor resection. Another application of laser fluorescence, already routinely used in our unit, is the systematic study of liver graft viability during the various steps of liver transplantation, ${ }^{10,11,12}$. To conclude, the objective of this professional activity in scientific investigation is to contribute to the generation of new knowledge that, once disseminated, can be used in the production of further knowledge or in the improvement of other human activities. Over a period of two decades we were able to advance from research to clinical application on the basis of experimental and clinical concepts, in our belief that these two activities cannot be dissociated. Obviously surgeons confront unique logistical problems when they are learning research methods and when they are attempting to practice research. Since excellence in surgery requires a high level of performance both in clinical judgment and technical application, the 
problem of integrating scholarly activities and clinical practice is usually more difficult for the surgeon than for academic physicians in other disciplines. However, personal discipline and dedication to the university permit reaching excellence in these activities which function, above all, as a form of personal growth that influences the scientific, teaching, assistance and administrative performance.

\section{The thematic supplement}

In view of the above considerations, Prof. Dr. Ajith Kumar Sankarankutty and myself decided to compile a series of studies conducted within the Division of Surgical Gastroenterology and publish them in a special issue in the form of a thematic Supplement, in order to disseminate our activities in clinical and experimental research in the area of surgical hepatology. The journal chosen was Acta Cirúrgica Brasileira because of its credibility as a vehicle and because of the credibility of its founder and Editor, Professor Saul Goldenberg, as the person who maintains the academicscientific credit of the journal. This time we chose the liver as the central topic around which a series of studies were compiled, most of them carried out by members of the Surgical Gastroenterology Division itself and essentially representing the production of knowledge, of reflections about current questions based on personal experience and on the literature, demonstrating the scope of our university function and ultimately reflecting the strong relationship existing between the research laboratory and the hospital.

\section{References}

1. Moore FD. The university in american surgery. Surgery. 1958; 44: 1-10.

2. Starzl TE. The puzzle people: memoirs of a tranplant surgeon. Pittsburgy: University of Pittsburgy Press; 1993.

3. Troidl H, Spitzer WO, McPeek B, Mulder DS, McKneally MF, Wechsler AS, Balch CM. Principles and practice of research. strategies for surgical investigators. New York: Springer-Verlag; 1991.

4. II Jornada de Investigação Científica. Departamento de Cirurgia e Anatomia da FMRP-USP. Pós-Graduação. Acta Cir Bras. 2002; 17(Suppl.3). Disponível em URL: http:// www.scielo.br/acb.

5. Bagnato VS, Kurachi C, Ferreira J, Sankarankutty AK, Zucoloto S, Castro e Silva O. New photonic technologies for the treatment and diagnosis of hepatic diseases: an overview of the experimental work performed in collaboration, between Physics Institute of São Carlos and Ribeirão Preto Faculty of Medicine of University of São Paulo. Acta Cir Bras [serial on the Internet] 2006;21 (Suppl.) Available from URL: http:// www.scielo.br/acb.

6. Castro e Silva O, Silva RL, Melo GB, Melo VA, Lima SO, Antoniolli ÂR, Bagnato VS. Proliferative effect of medicinal plants and laser on liver regeneration. A considerable experimental model: from an experimental model to clinical applications. Acta Cir Bras. 2003; 18: 68. Available from URL: http://www.scielo.br/acb.

7. Castro e Silva O, Zucoloto S, Beer A. Modelos experimentais de pesquisa em cirurgia. São Paulo: Robe Editorial; 1998.

8. Tolentino EC, Castro e Silva O, Zucoloto S, Souza MEJ, Gomes MCJ, Sankarankutty AK, Oliveira GR, Feres O. Effect of hyperbaric oxygen on liver regeneration in a rat model. Transp Proc. 2006 (in press).

9. Castro e Silva O, Sankarankutty AK, Martinelli ALC, Souza FF, Teixeira AC, Feres O, Mente ED, Oliveira GR, Akita R, Muglia V, Elias Jr J, Ramalho LNZ, Zucoloto S. Therapeutic effect of hyperbaric oxygen in hepatic artery thrombosis and functional cholestasis after orthotopic liver transplantation. Transp Proc. 2006 (in press).

10. Marcassa JC, Ferreira J, Zucoloto S, Castro e Silva O, Marcassa LG, Bagnato VS.Detection of hepatocarcinoma in rats by integration of the fluorescence spectrum: experimental model. Laser Physics. 2006; 16: 827-32.

11. Ferreira J, Kurachi C, Moriyama LT, Menezes PFC, Perussi JR, Sibata C, Zucoloto S, Castro e Silva O, Bagnato VS. Correlation between the photostability and photodynamic efficacy for different photosensitizers.Laser Phys Letter. 2006; 3:91-5.

12. Sankarankutty AK, Castro e Silva O, Ferreira J, MEJ Souza, Gomes, MCJ, Kurachi C, BagnatoVS. Use of laser auto-fluorescence for evaluating liver grafts Laser Phys. 2006 (in press). 